\author{
ANNALS OF THE \\ UNIVERSITY OF CRAIOVA
}

Series: $\begin{aligned} & \checkmark \text { Biology } \\ & \checkmark \text { Horticulture } \\ & \checkmark \text { Food products processing } \\ & \text { technology } \\ & \checkmark \text { Environmental engineering }\end{aligned}$

Vol. XXVI (LXII) - 2021

\title{
ESSENTIAL OILS AND TOTAL PHENOLIC CONTENT CORRELATED WITH ANATOMICAL FEATURES IN LAVANDULA ANGUSTIFOLIA MILL. ORGANS
}

\author{
Popoviciu Dan Răzvan ${ }^{1 *}$, Panaitescu Liliana ${ }^{1}$ \\ ${ }^{1}$ „Ovidius" University of Constanţa, Faculty of Natural Sciences and Agricultural Sciences, \\ Constanţa, Romania \\ *Correspondence author. E-mail: dr_popoviciu@yahoo.com
}

Keywords: Lavandula angustifolia, essential oils, phenolic compounds, anatomy

\begin{abstract}
Lavender (Lavandula angustifolia Mill.) organs from different vegetation years were analyzed anatomically and investigated for total phenolic compounds and essential oils content. Results were highly variate, with 1,064-13,043 mg/kg (DW) oil and 3,883-25,199 mg/kg phenolic compounds in stems and branches, 8,235-16,071 mg/kg oil and 1,603-33,300 mg/kg phenolics in leaves, $17,857 \mathrm{mg} / \mathrm{kg}$ oil and 60,563-67,156 mg/kg phenolics in flowers. Plant leaves and stems had rich, dense parenchymal tissues and secretory hairs. Leaves on current year twigs had both capitate (polysaccharid-secreting) and peltate (lipophilic-compound secreting) hairs. Fresh leaves, on flower-bearing twigs, as well as those on previous year twigs and fresh stems lacked peltate hairs, while older leaves and stems lacked secretory hairs.
\end{abstract}

\section{INTRODUCTION}

A member of the Lamiaceae family, lavender is an important crop in many regions of the world. It is cultivated for ornamental purposes, or for its volatile essential oils, used for aromatic, cosmetic, pharmaceutical and folk medicine purposes. It is a shrub that prefers warm and dry climates. Of the many extant species, Lavandula angustifolia Mill. is the most popular in Southeastern Europe, together with L. latifolia and hybrid cultivars (Huang et al. 2008, Brailko et al. 2017).

The main compounds of interest in lavender organs are essential oils. These are mostly volatile (over 90\%) mixtures of various polyphenols, including monoterpenes, sesquiterpenes and flavonoids, plus hydrocarbons and hydrocarbon derivatives, alcohols, aliphatic aldehydes, esters, etc. They are responsible for the specific aroma and have strong antibacterial and antioxidant abilities (Orphanides et al. 2011).

Phenolic and polyphenolic compounds include a wide range of chemicals, that serve as pigments or as antimicrobial and antifungal-protective compounds in plants. Among them, flavonoids, tannins, phenolic agents - they are one of the main sources of volatile oils. For human consumers, their main function is free radical scavenging and inhibiting lipid oxidation (Kivrak \& Kivrak 2014).

The aim of this research was to determine essential oil and total phenolic content in different plant organs from different years of vegetation and also to investigate variations in their anatomic structure. 


\section{MATERIAL AND METHODS}

Plant material was collected from local farms in Constanța county, Romania. Organs included fresh stems from the current vegetation year and stems in their second and third year, leaves from the current vegetation year and 2 and 3-year-old leaves, flower- bearing twigs and leaves from flower-bearing twigs (current year), flower buds and open flowers.

Plant organs were fixed in 5:5:90 formaldehyde: acetic acid: ethyl alcohol solution, cross-sectioned manually, stained with alum carmine and iodine green and analyzed through brightfield microscopy (Bercu \& Jianu, 2003).

For determining the concentration of total phenolic compounds, the spectrophotometric version of the Folin-Ciocâlteu method was used. Tissues were ground in methanol, filtered and and reacted with 10\% Folin-Ciocâlteu reagent and $7.5 \%$ sodium bicarbonate $(7.5 \%)$ for 30 minutes. Spectrophotometric absorbance was read at $765 \mathrm{~nm}$. A standard gallic acid calibration curve was used (Stanković 2011, Siddiqui et al. 2017, Popoviciu et al. 2020).

Essential oils were determined by grounding plant organs with petroleum ether $(5: 25 \mathrm{w} / \mathrm{w})$, evaporating the extracts at $35^{\circ} \mathrm{C}$ and weighing the residue (Orphanides et al. 2011, Popoviciu et al. 2020).

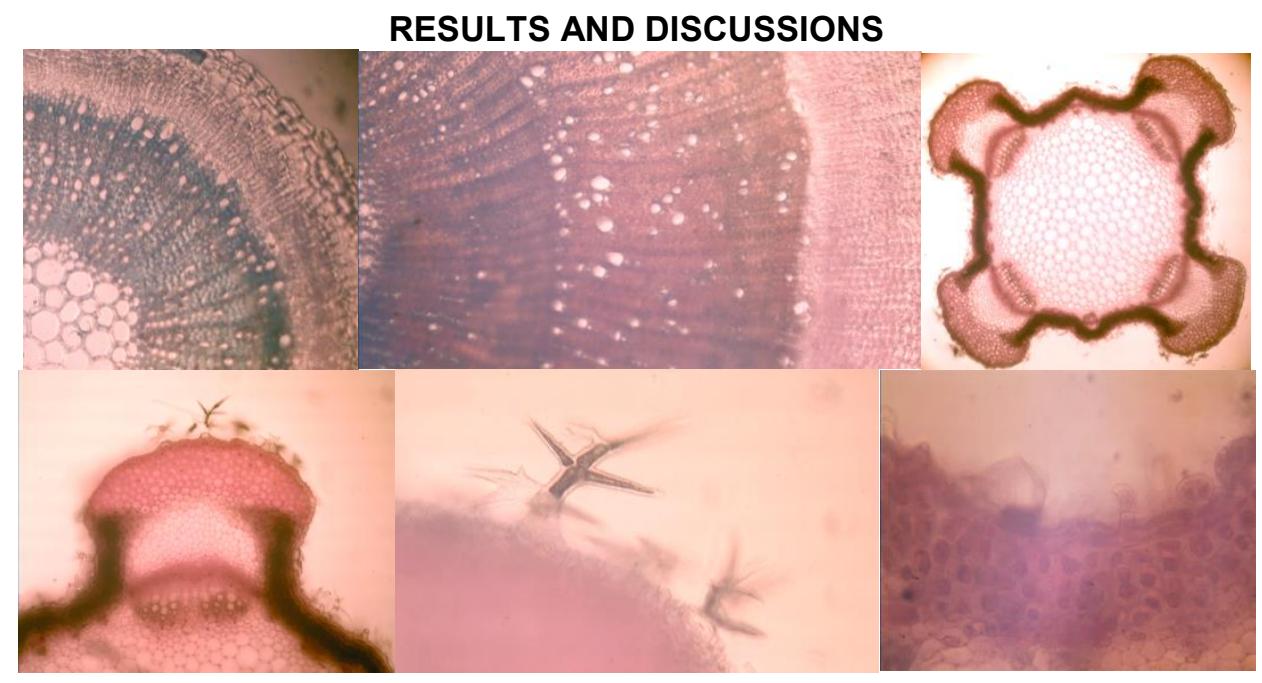

Figure 1. Stem anatomic features in Lavandula angustifolia: A) current year stems (100x); B) 3-yr-old stem, with growth rings (100x); C, D) Floriferous axis (40x, 100x); E) Protective hairs (200x); F) Secretory hairs (400x).

In their first year of vegetation, lavender stems already show an incipient secondary structure, with a compact vascular growth ring. The epidermis is rich in protective, branched hairs, while the cortex shows assemblies of mechanical fibers. The pit is well-developed, with abundant parenchymal cells (Fig. 1). 


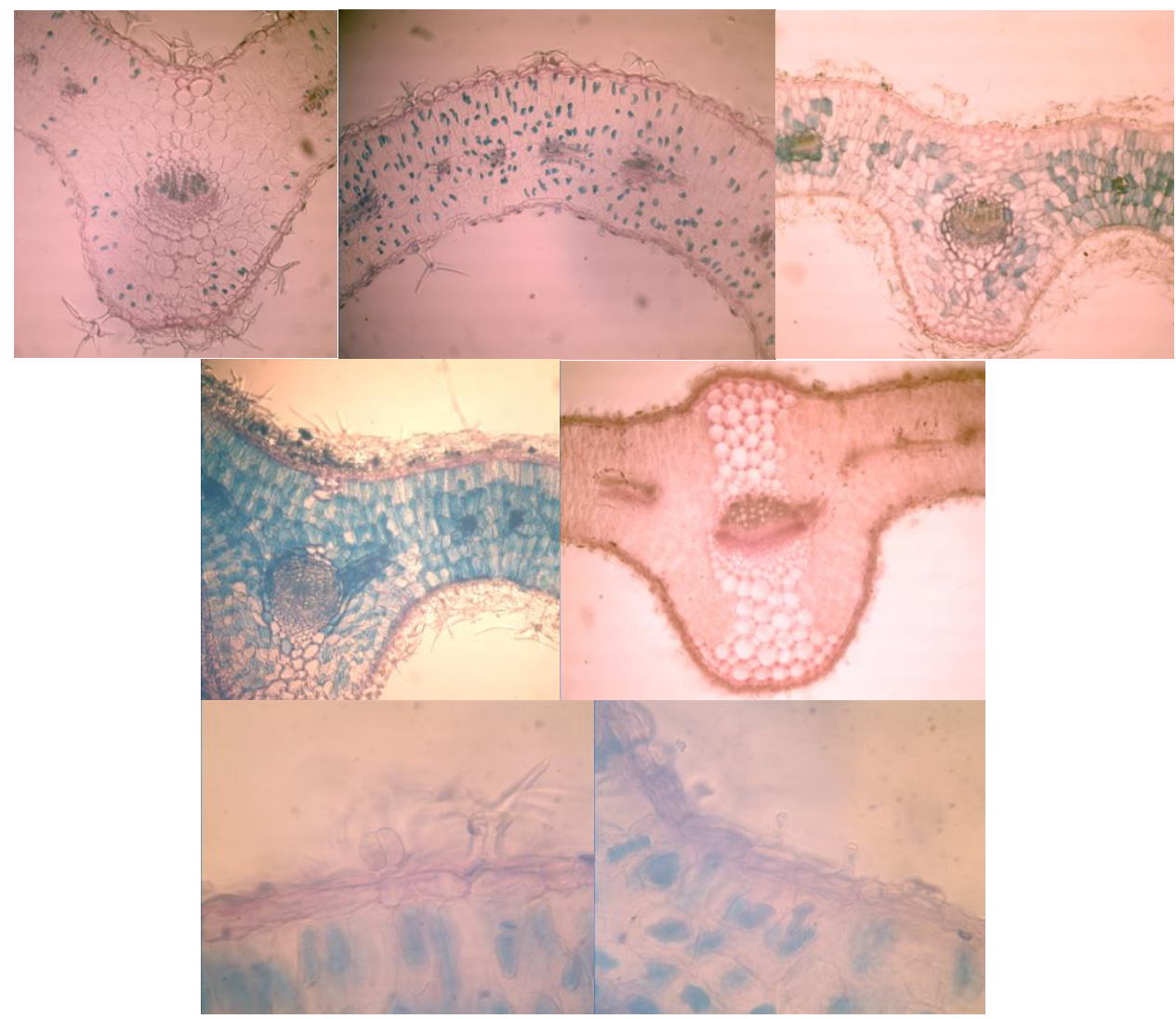

Figure 2. Leaf anatomic features in Lavandula angustifolia: A, B) current year leaves (100x); C, D) 2 and 3-yr-old leaves (100x); E) Leaf on floriferous axis (100x); F, G) Protective and secretory hairs (400x).

Flower-bearing stems show only a primary structure, with four separate collateral vascular bundles. These are located in the four corners of the stem, protected by massive collenchymatous ridges that give the typical stem shape of the Lamiaceae. Underneath each collenchymatous cap (Fig. 1D), a parenchymatous cortex region is located, composed of cells with dense cytoplasmatic/vacuolar content. On these new stems, hairs are variate, including protective hairs (multicellular, branched; Fig. 1E), capitate secretory hairs and rare peltate secretory hairs (Fig. 1F).

In their second and third year of vegetation, stems develop a typical secondary structure, with growth rings and cork.

Lavender leaves show a typical bifacial (although weakly differentiated) structure. The epidermis has a dense cover of protective and secretory hairs (both capitate and peltate; Fig. 2).

In their second year of vegetation, parenchymatous tissues undergo major morphological transformations, probably due to dehydration and accumulation of lignocellulosic compounds. Peltate glandular hairs decline in numbers, only capitate and protective ones remaining. In the third year, no glandular hairs were found. 
Leaves on flower-bearing twigs are similar to other new leaves described above, with a rich parenchyma, protective and secretory hairs (in this case, almost exclusively capitate).

Capitate trichomes (1-2 secretory cells on an elongated stalk; Fig. 2G) are known to secrete mostly polysaccharidic, but also lipophilic compounds. Peltate ones (groups of up to 8 cells; Fig. 2F) have only lipophilic secretions. They are both important in essential oil secretion, with the highest amount being attributed to capitate hairs (especially terpenes and $\beta$-Phellandrene, Huang et al. 2008).

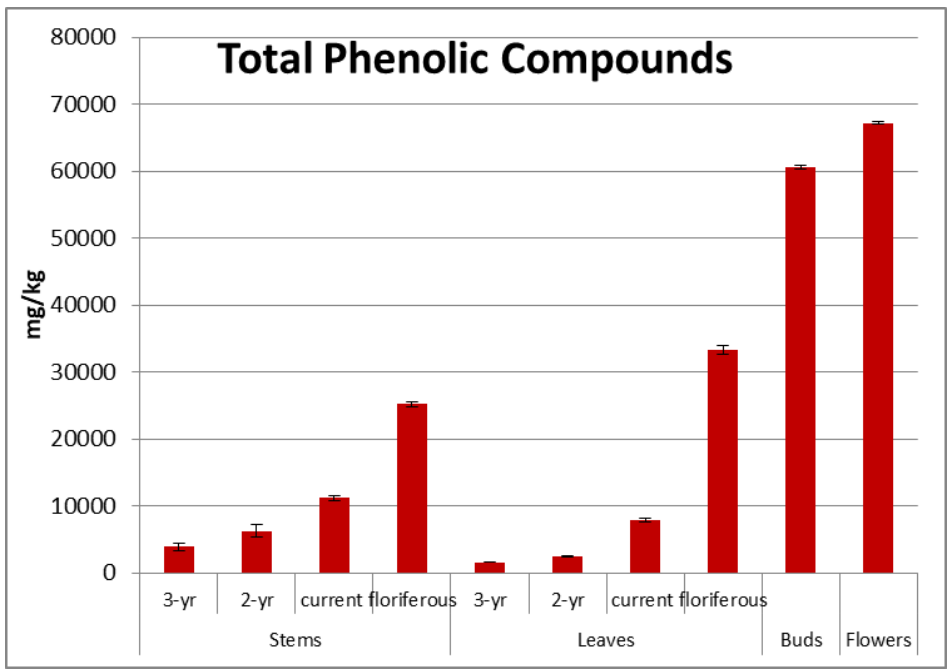

Figure 3. Concentration of total phenolic and polyphenolic compounds in Lavandula angustifolia organs (mg/kg GAE, dry weight).

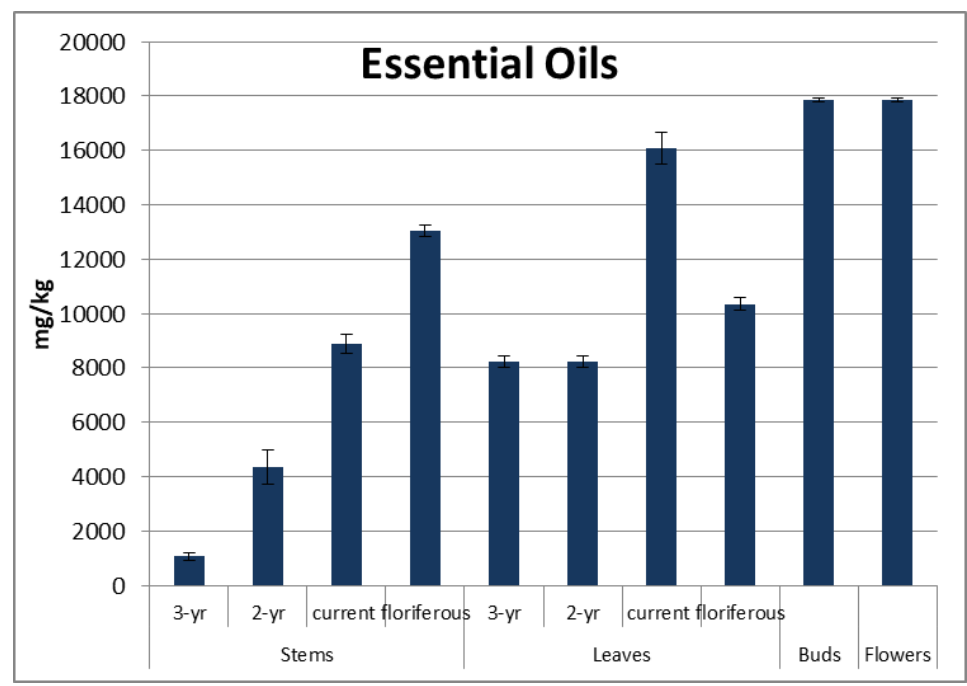

Figure 4. Concentration of volatile essential oils in Lavandula angustifolia organs (mg/kg, dry weight). 
Both stems and leaves showed a decrease of phenolic compounds and essential oils in the second and third years of vegetation. The highest values were found on floriferous axes: $33,300 \mathrm{mg} / \mathrm{kg} \mathrm{GAE}$ average phenolic content and 10,345 $\mathrm{mg} / \mathrm{kg}$ oils in leaves, respectively $25,199 \mathrm{mg} / \mathrm{kg}$ phenolic content and $13.043 \mathrm{mg} / \mathrm{kg}$ oils in stems. Generally, non-floriferous stems had a higher phenolic content $(3,882-$ $11,162 \mathrm{mg} / \mathrm{kg}$ ) than leaves $(1,603-7,839 \mathrm{mg} / \mathrm{kg})$. However, leaves had higher oil content $(8,235-16,041 \mathrm{mg} / \mathrm{kg}$, compared to $1,064-8,889 \mathrm{mg} / \mathrm{kg}$ in stems).

The highest amounts of both phenolic compounds $(60,563-67,156 \mathrm{mg} / \mathrm{kg})$ and essential oils $(17,857 \mathrm{mg} / \mathrm{kg})$ were found in flowers, with no major difference between flower buds and open flowers.

\section{CONCLUSIONS}

Total phenolic contents and essential oil content was highly variate in different lavender organs with 1,064-13,043 mg/kg (DW) oil and 3,883-25,199 mg/kg phenolic compounds in stems and branches, $8,235-16,071 \mathrm{mg} / \mathrm{kg}$ oil and 1,603$33,300 \mathrm{mg} / \mathrm{kg}$ phenolics in leaves, $17,857 \mathrm{mg} / \mathrm{kg}$ oil and $60,563-67,156 \mathrm{mg} / \mathrm{kg}$ phenolics in flowers.

Among vegetative organs, the highest amounts were found in flower-bearing twigs and their leaves, followed by other stems and leaves from the current vegetation year. A major decline was observed in organs in their second and third vegetation years.

This decline can be linked to changes in parenchymal structure of the organs and to a decrease in secretory trichomes numbers.

Leaves on current year twigs had both capitate (polysaccharid-secreting) and peltate (lipophilic-compound secreting) hairs. Fresh leaves, on flower-bearing twigs, as well as those on previous year twigs and fresh stems lacked peltate hairs, while older leaves and stems lacked secretory hairs.

\section{REFERENCES}

Bercu, R., Jianu, D.L., 2003. Practicum de morfologia si anatomia plantelor, Ovidius University Press, Constanța.

Brailko V., Mitrofanova O., Lesnikova-Sedoshenko N., Chelombit S., Mitrofanova I. 2017. Anatomy features of Lavandula angustifolia Mill. and Lavandula hybrida Rev. plants in vitro. Agriculture \& Forestry, 63(1), 111-117.

Huang S.S., Kirchoff B.K., Liao J.P. 2008. The capitate and peltate glandular trichomes of Lavandula pinnata L. (Lamiaceae): histochemistry, ultrastructure, and secretion. J. Torrey Bot. Soc., 135, 155-167.

Kivrak I., Kivrak S. 2014. Antioxidant properties, phenolic profile and nutritional value for Sorbus umbellata fruits from Turkey. Austin J. Nutr. Food Sci., 2(8), 1043-1048.

Orphanides A., Goulas V., Chrysostomou M., Gekas V. 2011. Recovery of essential oils from carobs through various extraction methods. In Mastorakis N., Mladenov V., Lepădătescu B., Karimi H.R., Helmis C.G. (eds.), Recent Advances in Environment, Energy Systems and Naval Science, WSEAS Press, Athens, 219-224.

Popoviciu D.R., Ionașcu, D.C., Bercu R. 2020. Comparative quantitative analysis of some classes of bioactive compounds in six green tea types available on the Romanian market. Ann. Univ. Craiova, Ser. Biol. Hortic. Food Prod. Process. Environ. Eng., 25(61): 167-172. 
Siddiqui N., Rauf A., Latif A., Mahmood Z. 2017. Spectrophotometric determination of the total phenolic content, spectral and fluorescence study of the herbal Unani drug Gul-e-Zoofa (Nepeta bracteata Benth). J. Taibah Univ. Med. Sci., 12(4), 360-363.

Stanković M.S. 2011. Total phenolic content, flavonoid concentration and antioxidant activity of Marrubium peregrinum L. extracts. Kragujevac J. Sci., 33, 63-72. 